\title{
ARTICLE OPEN \\ Obesity, low levels of physical activity and smoking present opportunities for primary care asthma interventions: an analysis of baseline data from The Asthma Tools Study
}

\author{
Barbara P Yawn ${ }^{1}$, Matthew A Rank ${ }^{2}$, Susan L Bertram³ and Peter C Wollan ${ }^{3}$
}

BACKGROUND: Asthma prevalence, severity and outcomes are associated with various patient characteristics and lifestyle choices. AIMS: To identify potentially modifiable factors associated with poor asthma outcomes among US primary care patients. METHODS: Using baseline data from the Asthma Tools Study, we calculated cross-sectional frequencies of activity levels, smoking, secondhand smoke exposure and the presence of obesity, as well as rates of out-of-control asthma and asthma exacerbations. Frequencies were stratified by sex, and into three age groups: 5-11 years, 12-18 years and 19 years and older. Logistic regression was used to identify factors associated with each of the asthma outcomes.

RESULTS: In the 901 individuals enrolled in this asthma study, tobacco smoke exposure, obesity, low activity levels, poverty, inadequately controlled asthma and high asthma-related health-care utilisation were common. Across all age groups, obesity was associated with poorer asthma outcomes: either poor asthma control (odds ratio $(\mathrm{OR})=2.3,95 \%$ confidence interval $(\mathrm{Cl}) 1.1-4.7$ in 5- to 11-year-olds and $\mathrm{OR}=1.5,95 \% \mathrm{Cl} 1.1-2.2$ in adults) or asthma exacerbations (OR 2.9, 95\% Cl 1.6-5.1 in 12- to 18-year-olds and OR 1.7, 95\% Cl 1.1-2.5 in adults). Among adults, smoking was associated with both measures of poorer asthma outcomes; inadequate asthma control $(\mathrm{OR}=2.3,95 \% \mathrm{Cl} 1.5-3.5)$, and asthma exacerbations ( $\mathrm{OR} 1.7,95 \% \mathrm{Cl} 1.1-2.6)$, and low physical activity were associated with poor asthma control $(\mathrm{OR}=1.5,95 \% \mathrm{Cl} 1.1-2.2)$.

CONCLUSIONS: Obesity, low levels of physical activity and smoking are common, and they are associated with poor asthma outcomes in a sample of primary care patients, suggesting important targets for intervention.

npj Primary Care Respiratory Medicine (2015) 25, 15058; doi:10.1038/npjpcrm.2015.58; published online 1 October 2015

\section{INTRODUCTION}

Asthma is common among US children and adults, with up to 1 in 8-11 children and 1 in 13 adults having received a physician diagnosis of asthma. ${ }^{1,2}$ Asthma continues to be associated with a significant burden to patients, families and health-care systems. ${ }^{3-6}$ That burden has been shown to be increased in certain age, sex, race/ethnicity and family income groups. ${ }^{7-11}$ These commonly enumerated factors are seldom amenable to medical interventions.

However, asthma prevalence, severity and outcomes are also associated with several potentially modifiable patient characteristics and lifestyle choices including level of obesity, $^{12-14}$ smoking status, ${ }^{15}$ levels of physical activity ${ }^{16}$ and exposure to secondhand smoke. ${ }^{8,17-20}$ Primary care physicians and practices provide the majority of asthma care ${ }^{5}$ and are therefore appropriate sites in which to assess the frequency of the additional potentially modifiable characteristics and lifestyle choices, highlighting opportunities to use nonmedication-based interventions to improve asthma outcomes.

This study uses the baseline data from a large pragmatic trial (The Asthma Tools Study) ${ }^{21}$ designed to assess the impact of introducing an asthma management tool (the Asthma APGAR system) into primary care practices. Here we present information on baseline demographic and behavioural characteristics of the enrolled patients and compare those with asthma outcomes at and in the year before enrollment. The goal is to identify potentially modifiable behavioural characteristics that might improve asthma outcomes.

\section{MATERIALS AND METHODS}

The overall description of the Asthma Tools Study has been published previously. ${ }^{21}$ In summary, the Asthma Tools Study is a 5-year pragmatic trial comparing Asthma APGAR system-guided asthma management with usual care in family medicine and paediatric community practices. Patient enrollment occurred between February 2011 and February 2014, and baseline data for each patient were collected from the 12 months before enrollment. Therefore, the period covered by this sub-study analysis is February 2010 through February 2014. We collected the baseline data using two methods: a patient-completed survey given to the patient/parent on the date of enrollment, and medical record review of all the patients' visits to the enrollment site for the 12 months before enrollment, not including the enrollment visit.

\section{Patients and practices}

Patients were enrolled from the 22 enrolled family medicine and paediatrics community practices. The practices were selected from primary care practices that were members of one or more practice-based research network, attempting to include sites from several regions of the US (SouthEast, NorthEast, MidWest, SouthWest and West Coast) and from rural areas, small- to medium-sized cities and large urban areas. (See designation on the map, Figure 1.) Patients were identified as having

\footnotetext{
'Department of Research, Olmsted Medical Center, Rochester, MN, USA; ${ }^{2}$ Division of Allergy, Asthma and Clinical Immunology, Mayo Clinic, Scottsdale, AZ, USA and ${ }^{3}$ Department of Research, Olmsted Medical Center, Rochester, MN, USA.

Correspondence: BP Yawn (byawn@olmmed.org)

Received 2 March 2015; revised 10 July 2015; accepted 31 July 2015
} 


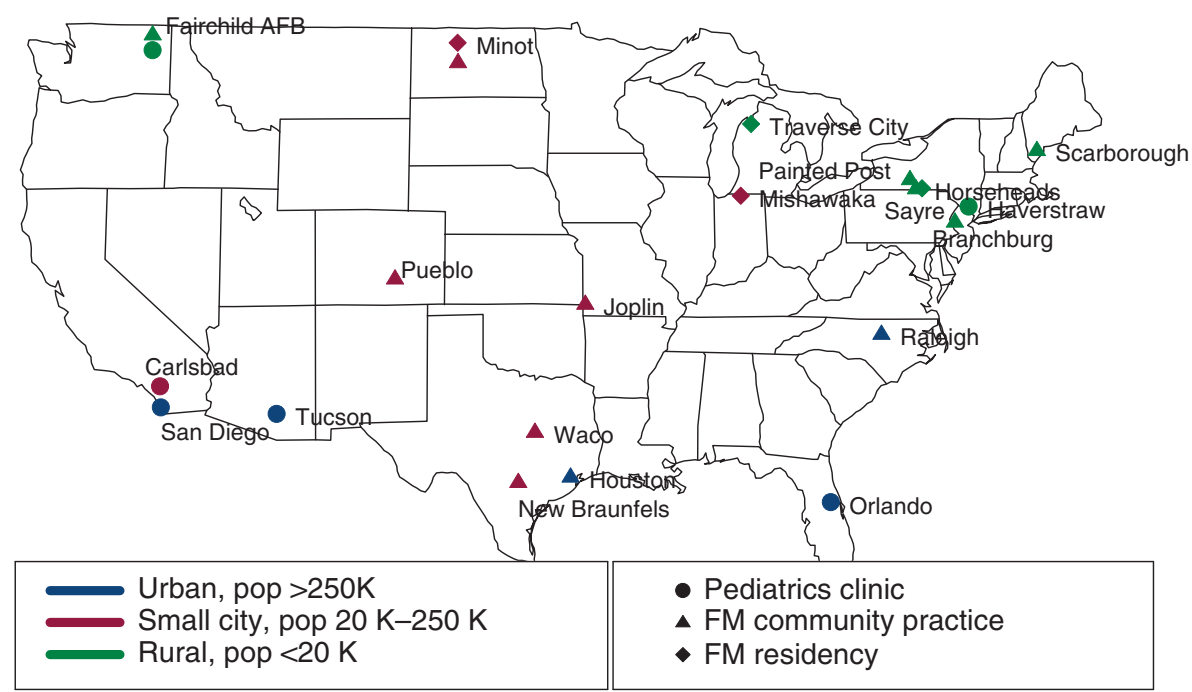

Figure 1. Practice sites by practice type and community size.

persistent asthma and identified by an asthma ICD-9 diagnostic code plus a current prescription for one or more daily maintenance medications from the practice's electronic health record or as patients meeting these characteristics visited the practice for asthma-related concerns. Of the patients offered enrollment, over $90 \%$ accepted.

\section{Data collection}

The baseline enrollment survey collected extensive patient/parentreported information on the following: patient's personal characteristics; asthma-related information-sources of asthma care; number of visits to the emergency department hospital; or receipt of oral or intramuscular steroids for asthma in the previous 6 months, as well as difficulty obtaining asthma care in the previous year. A measure of the enrolled patients' level of current asthma control was collected using the Asthma APGAR. ${ }^{22,23}$ The Asthma APGAR asks three questions about the frequency of activities that were missed or modified because of breathing problems, the frequency of daytime asthma symptoms and the frequency of night-time asthma symptoms over the previous weeks. An Asthma APGAR score of $>2$ is comparable to an Asthma Control Test score of $<20 .^{23,24}$ In addition to a 'control score', the Asthma APGAR asks questions about asthma triggers, use and adherence to asthma medications and the patient's assessment of the impact of their asthma medications. The responses are linked to a care algorithm recommending next steps of care. For the baseline period, the practices did not have access to the Asthma APGAR. (Asthma APGAR is displayed in the Supplementary Figure.)

The patient's age, sex, race/ethnicity, level of obesity, smoking status, estimated weekly activity levels, exposure to secondhand smoke and household income were all patient reported. Obesity was assessed on the basis of the patient's body mass index (BMI, height and weight) measured and documented in the patient's medical record during a visit in the baseline year. We required that both height and weight be measured (not patient estimate or report) at the same visit in children and adolescents and within the baseline year for adults, as adults are unlikely to gain height. The BMI for children aged 5 through 18 years is reported as the percentile on standard age-specific growth curves and summarised as underweight ( $<5 \%$ ), normal weight (5 to $85 \%$ ), overweight ( $>85$ to $95 \%$ ) and obese $(>95 \%){ }^{25,26}$ For adults, we used the US Center for Disease Control and Prevention (CDC) recommended cut-offs for underweight (BMI < 18.5), normal weight (BMI 18.5-24.9), overweight (25.0-29.9), obese (30.0-35.0) and morbidly obese (BMI > 35.0)..$^{27,28}$

The self-reported data were collected using previously developed or validated questions whenever possible. Smoking status, race/ethnicity and household income were collected using questions from the Behavioral Risk Factor Survey, ${ }^{29}$ the National Health Interview Survey ${ }^{30}$ or Medical Expenditure Panel Survey. ${ }^{31}$ When we found no standardised or validated question, we developed questions specifically for this study. Activity frequency was asked on a daily basis, which allowed collapse into longer periods. The levels of activity queried (moderate or strenuous) were adapted from the 2000 International Physical Activity Questionnaire, ${ }^{32}$ and results were compared with the 2010 CDC recommendations for physical activity. ${ }^{33,34}$ The questions on secondhand smoke exposure were designed to address the sights where children, adolescents and adults spend significant portions of time that are not regulated by indoor smoking laws: e.g., home and cars. The questions included in the baseline survey are in Supplementary Table 1.

We chose to present results within age groupings similar to those used in the US national asthma guidelines-e.g., 5 through 11 years, 12 through 18 years and 19 years and older, and labelled the groups as children, tweens and adults, respectively. ${ }^{35}$

The asthma control outcome is based on the patient/parent's completed Asthma APGAR score, with a score of $>2$ considered to be inadequate control. $^{22,23}$ To compare patient-perceived asthma control with that from a validated objective metric, we used the final question from the Asthma Control Test, which asks patients to report their perceived level of asthma control. $^{24}$

Overall, 1,176 patients were enrolled in the Asthma Tools study between 2011 and 2014. Of the enrolled patients, 901 (77\%) returned a useable baseline survey; e.g., responses were completed to over $90 \%$ of survey items. The rates of return varied among the enrolled patients from $76 \%$ in children to $73 \%$ in tweens and $67 \%$ in men to $83 \%$ in women $(P=0.03)$ Across all age groups, male patients were less likely than female patients to return the survey, although the differences were only significant for the adults. Among the adults, younger individuals $(P<0.0001)$ and those with higher BMIs $(P<0.05)$ were also less likely to return baseline surveys.

\section{Data analysis}

Patient characteristics were tabulated, and percentages were computed based on the individuals responding to the item. Characteristics were compared using Wilcoxon rank-sum tests for numeric data and Chi-squared tests for frequencies. Logistic regression was used to identify characteristics associated with asthma control, as determined by Asthma APGAR $>2$ and for asthma exacerbations determined by self-reported emergency department (ED) or hospital visits or steroid bursts for asthma. For multivariable modelling, a step-down procedure was used, starting with all variables and removing those with the highest $P$ values first. All analyses were completed in S-Plus v. 7.0.6 (Tibco, Boston, MA, USA).

\section{RESULTS}

Demographics of the primary care asthma sample

Table 1 summarises the demographic information for the 901 primary care patients included in this sub-study. Enrollment rates by sex reflect the known higher prevalence of asthma in boys, reversing to more women than men in adulthood. The population is racially and ethnically diverse with $20 \%$ or more Hispanic individuals in each age group but decreasing numbers of 
Table 1. Demographic and self-reported behaviors

\begin{tabular}{|c|c|c|c|}
\hline \multirow{3}{*}{$\begin{array}{l}\text { Characteristics by age group } \\
\text { Children ( } 5-11 \text { years) }\end{array}$} & \multicolumn{3}{|c|}{$\begin{array}{l}\text { Enrolled and returned } \\
\text { baseline survey } N=893\end{array}$} \\
\hline & All & Boys & Girls \\
\hline & $N=216$ & $N=137$ & $N=79$ \\
\hline Age in years: mean & $\begin{array}{c}8.4 \\
\%\end{array}$ & $\begin{array}{c}8.5 \\
\%\end{array}$ & $\begin{array}{c}8.3 \\
\%\end{array}$ \\
\hline \multicolumn{4}{|l|}{ Race/ethnicity } \\
\hline White & 66.7 & 64.7 & 67.1 \\
\hline Black & 26.7 & 26.3 & 25.3 \\
\hline Native American & 0.3 & 0.8 & 0 \\
\hline Asian & 4.0 & 5.3 & 5.1 \\
\hline Other/none & 2.3 & 3.0 & 2.5 \\
\hline Hispanic & 24.7 & 26.3 & 29.1 \\
\hline \multicolumn{4}{|l|}{ Family income per year } \\
\hline$<\$ 10,000$ & 15.9 & 17.0 & 13.9 \\
\hline$\$ 10,000$ to $\$ 24,999$ & 21.0 & 20.7 & 21.5 \\
\hline$\$ 25,000$ to $\$ 49,999$ & 20.1 & 17.1 & 25.3 \\
\hline$\geqslant \$ 50,000$ & 39.7 & 40.8 & 38.0 \\
\hline Not reported & 3.3 & 4.4 & 1.3 \\
\hline \multicolumn{4}{|l|}{$B M I$} \\
\hline$\%$ Obese & 21.4 & 16.9 & 29.0 \\
\hline$\%$ Overweight & 14.0 & 14.6 & 13.1 \\
\hline$\%$ Healthy & 56.5 & 59.6 & 51.4 \\
\hline$\%$ Underweight & 3.5 & 5.1 & 0.9 \\
\hline$\%$ Not available & 4.6 & 3.9 & 5.6 \\
\hline \multicolumn{4}{|l|}{ Smoking } \\
\hline$\%$ Any secondhand smoke & 35.7 & 35.6 & 35.8 \\
\hline 5-7 Days per week ever & 21.1 & 21.8 & 20.3 \\
\hline 5-7 Days per week now & 12.7 & 12.8 & 12.7 \\
\hline \multicolumn{4}{|l|}{ Activity level } \\
\hline \multicolumn{4}{|l|}{ \% Doing moderate activity } \\
\hline$\geqslant 3$ Times a week, $15 \mathrm{~min}$ & 64.4 & 65.0 & 63.3 \\
\hline$\geqslant 5$ Times a week, $15 \mathrm{~min}$ & 39.4 & 39.4 & 39.2 \\
\hline \multicolumn{4}{|l|}{ \% Doing strenuous activity } \\
\hline$\geqslant 3$ Times a week, $15 \mathrm{~min}$ & 58.3 & 52.0 & 62.0 \\
\hline$\geqslant 5$ Times a week, $15 \mathrm{~min}$ & 29.6 & 36.5 & 17.7 \\
\hline $\begin{array}{l}\text { Parent-reported use of influenza vaccine } \\
\text { (\% always or usually) }\end{array}$ & 69.4 & 67.9 & 72.2 \\
\hline Allergy testing ever, $\%$ yes & 43.3 & 45.9 & 38.0 \\
\hline Needed asthma care and could not get it & 6.1 & 7.5 & 3.9 \\
\hline Tweens (12-18 years) & $\begin{array}{c}\text { All } \\
N=153\end{array}$ & $\begin{array}{l}\text { Boys } \\
N=83\end{array}$ & $\begin{array}{l}\text { Girls } \\
N=70\end{array}$ \\
\hline Age in years: mean $^{a}$ & 15.2 & 14.7 & 15.8 \\
\hline \multicolumn{4}{|l|}{ Race/ethnicity } \\
\hline White & 78.4 & 75.6 & 82.1 \\
\hline Black & 14.4 & 20.0 & 11.9 \\
\hline Native American & 1.3 & 2.3 & 0 \\
\hline Asian & 2.6 & 3.5 & 1.5 \\
\hline Other/none & 3.7 & 2.3 & 4.5 \\
\hline Hispanic & 24.8 & 22.1 & 28.4 \\
\hline \multicolumn{4}{|l|}{ Family income per year } \\
\hline$<\$ 10,000$ & 13.8 & 8.2 & 20.9 \\
\hline$\$ 10,000$ to $\$ 24,999^{a}$ & 17.1 & 18.8 & 14.9 \\
\hline$\$ 25,000$ to $\$ 49,999$ & 16.4 & 15.3 & 17.9 \\
\hline$\geqslant \$ 50,000$ & 45.4 & 49.5 & 40.3 \\
\hline Not reported & 7.2 & 8.2 & 6.0 \\
\hline \multicolumn{4}{|l|}{$B M I$} \\
\hline$\%$ Obese & 27.5 & 28.3 & 26.5 \\
\hline$\%$ Overweight & 19.0 & 14.2 & 24.5 \\
\hline$\%$ Healthy & 43.1 & 46.0 & 39.8 \\
\hline$\%$ Underweight & 3.8 & 6.2 & 1.0 \\
\hline$\%$ Not available in 1 year & 6.6 & 5.3 & 8.2 \\
\hline \multicolumn{4}{|l|}{ Smoking - } \\
\hline Primary & 1.3 & 1.3 & 1.5 \\
\hline Secondhand smoke (any) & 54.1 & 49.4 & 59.7 \\
\hline
\end{tabular}

Table 1. (Continued)

\begin{tabular}{|c|c|c|c|}
\hline Tweens (12-18 years) & $\begin{array}{c}\text { All } \\
N=153\end{array}$ & $\begin{array}{c}\text { Boys } \\
N=83\end{array}$ & $\begin{array}{c}\text { Girls } \\
N=70\end{array}$ \\
\hline $\begin{array}{l}\text { 5-7 Days per week ever } \\
\text { 5-7 Days per week now }\end{array}$ & $\begin{array}{l}24.8 \\
17.0\end{array}$ & $\begin{array}{l}24.4 \\
18.6\end{array}$ & $\begin{array}{l}25.4 \\
14.9\end{array}$ \\
\hline $\begin{array}{l}\text { Activity level } \\
\% \text { Doing moderate activity } \\
\geqslant 3 \text { times a week, } 15 \mathrm{~min} \\
\geqslant 5 \text { times a week, } 15 \mathrm{~min} \\
\% \text { Doing strenuous activity } \\
\geqslant 3 \text { Times a week, } 15 \mathrm{~min} \\
\geqslant 5 \text { Times a week, } 15 \mathrm{~min}\end{array}$ & $\begin{array}{l}58.2 \\
30.7 \\
51.0 \\
28.1\end{array}$ & $\begin{array}{l}55.8 \\
30.2 \\
53.5 \\
30.2\end{array}$ & $\begin{array}{l}61.2 \\
31.3 \\
47.8 \\
25.4\end{array}$ \\
\hline $\begin{array}{l}\text { Self-reported use of influenza vaccine } \\
\text { (\% always or usually) } \\
\text { Allergy testing ever, } \% \text { yes } \\
\text { Needed asthma care and could not get it }\end{array}$ & $\begin{array}{c}64.7 \\
44.7 \\
6.8\end{array}$ & $\begin{array}{c}65.0 \\
44.2 \\
6.3\end{array}$ & $\begin{array}{c}64.2 \\
44.8 \\
7.6\end{array}$ \\
\hline Adults $>18$ years (19-60 years) & $\begin{array}{c}A l l \\
N=533\end{array}$ & $\begin{array}{c}\text { Men } \\
N=128\end{array}$ & $\begin{array}{l}\text { Women } \\
N=405\end{array}$ \\
\hline Age in years: mean & 40.6 & 39.8 & 40.9 \\
\hline $\begin{array}{l}\text { Race/ethnicity } \\
\text { White } \\
\text { Black } \\
\text { Native American } \\
\text { Asian } \\
\text { Other/none } \\
\text { Hispanic }\end{array}$ & $\begin{array}{l}89.3 \\
7.9 \\
1.0 \\
1.0 \\
1.0 \\
3.9\end{array}$ & $\begin{array}{l}91.4 \\
3.9 \\
2.3 \\
1.6 \\
0.8 \\
5.5\end{array}$ & $\begin{array}{l}88.6 \\
8.4 \\
1.0 \\
1.0 \\
1.0 \\
4.2\end{array}$ \\
\hline $\begin{array}{l}\text { Family income/year } \\
<\$ 10,000 \\
\$ 10,000 \text { to } \$ 24,999 \\
\$ 25,000 \text { to } \$ 49,999 \\
\geqslant \$ 50,000^{\mathrm{a}} \\
\text { Not reported } \\
\text { BMI (mean and range) } \\
\\
\text { \% Morbidly obese } \\
\% \text { Obese } \\
\% \text { Overweight } \\
\% \text { Normal weight } \\
\% \text { Under weight } \\
\% \text { Not reported }\end{array}$ & $\begin{array}{c}16.5 \\
16.5 \\
19.2 \\
45.9 \\
1.9 \\
32.6 \\
(12-71) \\
16.8 \\
33.6 \\
25.2 \\
15.0 \\
0.4 \\
9.0\end{array}$ & $\begin{array}{c}10.9 \\
10.9 \\
20.3 \\
56.3 \\
1.6 \\
30.9 \\
(12-52) \\
8.6 \\
32.0 \\
34.4 \\
7.8 \\
1.6 \\
15.6\end{array}$ & $\begin{array}{c}18.3 \\
18.3 \\
18.7 \\
42.7 \\
2.0 \\
33.1 \\
(19-71) \\
19.4 \\
34.1 \\
22.4 \\
17.2 \\
0 \\
6.9\end{array}$ \\
\hline $\begin{array}{l}\text { Smoking } \\
\text { Primary } \\
\text { Secondhand smoke (any) } \\
\text { 5-7 Days per week ever } \\
\text { 5-7 Days per week now }\end{array}$ & $\begin{array}{l}15.4 \\
60.7 \\
64.2 \\
22.5\end{array}$ & $\begin{array}{l}13.3 \\
60.3 \\
62.5 \\
18.8\end{array}$ & $\begin{array}{l}16.0 \\
60.8 \\
64.7 \\
23.7\end{array}$ \\
\hline 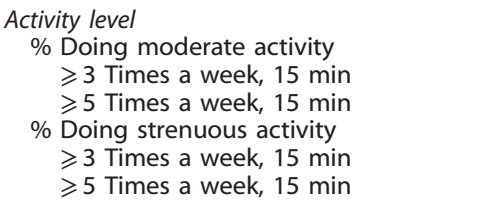 & $\begin{array}{c}39.8 \\
18.5 \\
24.0 \\
9.0\end{array}$ & $\begin{array}{l}43.0 \\
23.4 \\
37.5 \\
15.6\end{array}$ & $\begin{array}{c}38.8 \\
17.5 \\
19.8 \\
6.9\end{array}$ \\
\hline $\begin{array}{l}\text { Self-reported use of influenza vaccine } \\
\text { (\% always or usually) } \\
\text { Allergy testing ever, } \% \text { yes } \\
\text { Needed asthma care and could not get it }\end{array}$ & $\begin{array}{l}57.2 \\
20.8\end{array}$ & $\begin{array}{l}63.3 \\
15.7\end{array}$ & $\begin{array}{l}54.6 \\
21.9\end{array}$ \\
\hline
\end{tabular}

nonwhite individuals across increasing age groups. The annual family income was low for these patients with $42 \%$ of the children, $31 \%$ of tweens and $33 \%$ of adults living in a household with annual household incomes $\leqslant \$ 25,000$, which is approximately the 2011 Federal poverty level for a household of three or more. ${ }^{36}$

Across all age groups, more than $35 \%$ of the asthma patients had BMls considered to be in the overweight or obese range. It means that $35 \%$ of the children and $46 \%$ of the tweens 
had BMIs at or above the 85 percentile of weight for all similarly aged children or tweens of the same sex. Overall, $46 \%$ of the adults had a BMl of 25 or greater. Exposure to tobacco smoke was common among all enrollees, with more than 1 in 8 adults reporting themselves as smokers with daily secondhand smoke exposure in 1 in 8 children, 1 in 6 tweens and 1 in 4 adults.

Self- or parent-reported activity decreased with age. Although $30 \%$ of children and $28 \%$ of tweens met or exceeded the CDC's recommendation for levels of weekly activity of 15 or more minutes of moderate activity 5 or more days a week, only $9 \%$ of adults met the recommended 15 or more minutes of moderate activity 5 or more days per week. ${ }^{33,34}$ Girls and women were less likely than boys or men to do at least 15 or more minutes of strenuous activity 5 or more days per week.

Patient assessments versus objective assessment of asthma control and quality of life

Almost half of this cohort had inadequate asthma control according to the patient-completed Asthma APGAR. ${ }^{22,23}$ Higher rates of inadequate control were reported in tween girls compared with tween boys and women compared with men (Table 2). Despite high rates of objective assessment of inadequate asthma control, only about $10 \%$ of tweens and $15 \%$ of adults said their asthma was not in control, as defined by the final question of Asthma Control Test. ${ }^{23,24}$ The Childhood Asthma Control Test does not include this question.

Asthma-related ED or urgent care visits in the past 6 months were common in all ages but highest in children (5- to 11-yearold), in whom almost 1 in 4 reported that they made such a visit. The rates dropped in tween (12- to 18-year-old) boys, but rates remained high among tween girls. The sex differences in rates of ED visits continued into adulthood (Table 2). Rates of frequent ED or urgent care visits, e.g., three or more in the previous 6 months, were more common in female patients of all ages compared with male patients, but did decline with increasing age $(7.8 \%$ of children, $3.4 \%$ of tweens and $3.6 \%$ of adults). Hospitalisations also demonstrated the same sex differential as ED visits, across all ages (Table 2).

Even with the high rates of urgent care and ED visits, over 1 in 10 tweens and 1 in 5 adults reported inability to obtain needed asthma care at least once in the baseline year. We did not ask the question for children aged 5-11 years.

Logistic regression to identify associations with asthma control and exacerbations

Several individual socio-demographic and behavioural factors were associated with out-of-control asthma, and the factors differed by age group. Univariable analysis results are in Supplementary Table 2. Among children, out of control asthma was associated with annual family income $<\$ 50,000$ and being overweight. No factors were found to be significant in tween groups aged 12 through 18 years, perhaps because of our limited sample of tweens. In adults, female gender, Black race, annual family income less than $\$ 50,000$, less than 15 min of activity 5 or more days a week, smoking and obesity were each individually associated with out-of-control asthma. In multivariable modelling, adding in all the factors that were individually associated with outof-control asthma, only annual family income $<\$ 50,000$ was significant for children, although obesity showed a trend towards significance $(P=0.06)$ and for adults family income $<\$ 50,000$, smoking and obesity remained jointly significant (Table 3 ). Among adults, the likelihood of having out-of-control asthma increased with increasing $\mathrm{BMI}$ across the entire spectrum of weight from underweight to morbid obesity ( $P=0.005$ for a linear trend).

The factors associated with having one or more asthma exacerbations during the previous 6 months were slightly
Table 2. Self-reported asthma outcomes by age group

Asthma-related outcomes

Enrolled and returned baseline

by age group survey $\mathrm{N}=893$

\begin{tabular}{|c|c|c|c|}
\hline Children (5-11) & $\begin{array}{c}\text { All } \\
\mathrm{N}=214\end{array}$ & $\begin{array}{l}\text { Boys } \\
N=137\end{array}$ & $\begin{array}{l}\text { Girls } \\
\mathrm{N}=79\end{array}$ \\
\hline$\%$ Asthma out of control ${ }^{+}$ & 56.0 & 58.5 & 51.9 \\
\hline \multicolumn{4}{|l|}{$\%$ With asthma visits to: } \\
\hline ED/urgent & 27.3 & 29.9 & 23.1 \\
\hline Hospital & 6.2 & 3.9 & 9.1 \\
\hline Steroid burst $\leqslant 1$ previous year & 32.7 & 30.4 & 36.7 \\
\hline Steroid burst $>1$ previous year & 13.1 & 10.1 & 14.8 \\
\hline \% With an 'exacerbation' & 34.3 & 38.3 & 27.8 \\
\hline AQLQ_mean & 5.2 & 5.1 & 5.3 \\
\hline Tweens (12-18) & $\begin{array}{c}\text { All } \\
N=153\end{array}$ & $\begin{array}{l}\text { Boys } \\
N=83\end{array}$ & $\begin{array}{l}\text { Girls } \\
N=70\end{array}$ \\
\hline$\%$ Asthma out of control ${ }^{+, a}$ & 52.0 & 45.9 & 59.7 \\
\hline$\%$ Self-reported asthma out of control & 10.0 & 10.1 & 11.3 \\
\hline \multicolumn{4}{|l|}{$\%$ With asthma visits to: } \\
\hline ED/urgent & 18.5 & 15.2 & 22.3 \\
\hline Hospital & 2.8 & 1.3 & 4.6 \\
\hline Steroid burst $\leqslant 1$ previous year & 18.4 & 17.6 & 19.4 \\
\hline Steroid burst $>1$ previous year & 6.5 & 5.9 & 7.4 \\
\hline \% With an 'exacerbation' & 14.1 & 13.0 & 15.4 \\
\hline AQLQ-mean & 5.2 & 5.3 & 5.0 \\
\hline $\begin{array}{l}\text { Adults }>18 \text { years } \\
(19-60)\end{array}$ & $\begin{array}{c}\text { All } \\
N=533\end{array}$ & $\begin{array}{c}\text { Men } \\
N=128\end{array}$ & $\begin{array}{l}\text { Women } \\
N=405\end{array}$ \\
\hline$\%$ Asthma out of control ${ }^{+, a}$ & 61.2 & 53.1 & 63.7 \\
\hline$\%$ Out of control by self report & 15.9 & 14.1 & 16.5 \\
\hline \multicolumn{4}{|l|}{$\%$ With asthma visits to: } \\
\hline ED/urgent & 18.8 & 12.1 & 19.1 \\
\hline Hospital & 3.5 & 1.6 & 4.0 \\
\hline Steroid burst $\leqslant 1$ previous year & 20.0 & 18.0 & 20.6 \\
\hline Steroid burst $>1$ previous year & 9.0 & 7.8 & 9.3 \\
\hline \% With an 'exacerbation' & 23.2 & 17.9 & 24.9 \\
\hline AQLQ_mean & 5.0 & 5.3 & 4.9 \\
\hline
\end{tabular}

different from those for out-of-control asthma. In children, only annual family income of $<\$ 50,000$ was significant in both univariable and multivariable modelling. For the tween group, both obesity and Black race were significant in univariable and multivariable modelling. For adults 19 years and older, Black race, annual family income $<\$ 50,000$, obesity and smoking were each significantly associated with asthma exacerbations. Race, obesity and smoking remained significant in multivariable logistic regression in adults (Table 4 ).

\section{DISCUSSION}

\section{Main findings}

This group of children, tweens and adults have multiple adverse health and asthma risk factors. They are commonly exposed to tobacco smoke, often overweight, have modest levels of physical activity, limited family incomes, significant asthma-related health-care utilisation of urgent, emergent and hospital care, high rates of out-of-control asthma and a significant self-reported unmet need for asthma care. These characteristics suggest multiple opportunities for intervention and highlight potential barriers that family physicians and paediatricians face in providing asthma care to their patients. 
Table 3. Factors associated with out-of-control asthma

\begin{tabular}{|c|c|c|c|}
\hline By age group & Factor & $\begin{array}{l}\text { Odds ratio } \\
\text { (Cl 95\%) }\end{array}$ & P-value \\
\hline \multicolumn{4}{|l|}{$5-11$ years } \\
\hline \multirow[t]{2}{*}{ Univariable } & Obesity $^{\mathrm{a}}$ & $2.3(1.1-4.7)$ & 0.03 \\
\hline & $\begin{array}{l}\text { Family income } \\
<\$ 50,000\end{array}$ & $1.5(1.1,2.0)$ & 0.007 \\
\hline Multivariable & $\begin{array}{l}\text { Family income } \\
<\$ 50,000\end{array}$ & $1.5(1.1,2.0)$ & 0.007 \\
\hline $12-18$ Years & \multirow{2}{*}{\multicolumn{3}{|c|}{ No factors are significant }} \\
\hline $19+$ Years & & & \\
\hline \multirow{6}{*}{ Univariable } & Smoking ${ }^{c}$ & $2.3(1.5,3.5)$ & $<0.001$ \\
\hline & $\begin{array}{l}\text { Family income } \\
<\$ 50,000\end{array}$ & $2.1(1.5,3.0)$ & $<0.001$ \\
\hline & Race (Blacks) ${ }^{d}$ & $2.2(1.03,4.8)$ & 0.02 \\
\hline & Morbid obesity & $1.5(1.1,2.2)$ & 0.008 \\
\hline & Less activity ${ }^{\mathrm{e}}$ & $1.5(1.1,2.2)$ & 0.01 \\
\hline & Gender (female) & $1.6(1.04,2.3)$ & 0.02 \\
\hline \multirow[t]{3}{*}{ Multivariable } & Smoking & $1.7(1.1,2.7)$ & 0.01 \\
\hline & Morbid obesity & $1.7(1.1,3.0)$ & 0.02 \\
\hline & $\begin{array}{l}\text { Family income } \\
<\$ 50,000\end{array}$ & $1.6(1.1,2.4)$ & 0.01 \\
\hline
\end{tabular}

Variables considered are as follows: age, gender, race, income, activity, flu vaccination, smoke exposure and obesity. Variables were fit singly (univariate modelling), and then a stepwise procedure examined all the variables together.

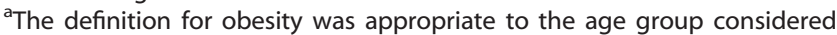
and varied for those $<19$ and adults. ${ }^{37,38}$ Non-obese was the reference group.

${ }^{\mathrm{b}}$ Family income was self reported as total annual family income with reference group income of $\geqslant \$ 50,000 /$ year.

'Smoking was self reported; current smoking status and nonsmoking was the reference group.

${ }^{d}$ Race was self-reported race. White was the reference group.

${ }^{\mathrm{e}}$ Activity was self reported as the number of times per week with $15 \mathrm{~min}$ or more of moderate and $15 \mathrm{~min}$ or more of strenuous activity (examples given). Higher levels of activity, at least 15 min of moderate activity five or more times per week or 15 or more minutes of strenuous activity two or more times per week.

Interpretation of findings in relation to previously published work Among our group of patients, smoking was significantly associated with both out-of-control asthma and asthma exacerbations among the adults. This provides further support for the need to address smoking at each visit, as repeated attempts for smoking cessation supported by combination therapy can reduce smoking rates significantly. ${ }^{37,38}$ The self-reported rates of tobacco use of these adults are similar to the overall US population for women ( $16.0 \%$ vs. $15.8 \%$ for US) but significantly lower among the men $(13.3 \%$ vs. $20.5 \%$ for US, $P<0.01) .{ }^{39}$ Whether this result reflects men's enhanced smoking abstinence in the face of asthma or differences in reporting choices is unknown, but worth further exploration in other populations of adults with asthma. The selfreported smoking rates of tweens are very low and may represent reluctance of the tweens to report smoking on a survey reviewed by their parents.

Although secondhand smoke exposure did not rise to the level of statistical significance in relation to poor asthma outcomes, tobacco smoke is a well-recognised trigger for asthma symptoms and exacerbations. ${ }^{17-19}$ Exposure to any secondhand smoke was common among these patients varying from about 1 in 3 children to over half of adults, with more than 1 in 10 of these individuals exposed to daily secondhand smoke. However, physicians and other clinicians do not often assess or at least document environmental tobacco smoke exposure. ${ }^{40,41}$ Any visit related to asthma, especially those for an exacerbation or review of asthma, should include a query, documentation and offer to support
Table 4. Factors associated with $\geqslant 1$ asthma exacerbations in previous 6 months

\begin{tabular}{|c|c|c|c|}
\hline By age group & Factor & $\begin{array}{l}\text { Odds ratio } \\
\text { (Cl 95\%) }\end{array}$ & P-value \\
\hline \multicolumn{4}{|l|}{ 5-11 Years } \\
\hline Univariable & $\begin{array}{l}\text { Family income }{ }^{a} \\
<\$ 50,000\end{array}$ & $1.5(1.1,2.0)$ & 0.01 \\
\hline Multivariable & $\begin{array}{l}\text { Family income } \\
<\$ 50,000\end{array}$ & $1.5(1.1,2.0)$ & 0.01 \\
\hline \multicolumn{4}{|l|}{$12-18$ Years } \\
\hline \multirow[t]{2}{*}{ Univariable } & Obesity $^{\mathrm{b}}$ & $2.9(1.6,5.1)$ & $<0.0001$ \\
\hline & Race $^{c}$ & $0.3(0.1,0.9)$ & 0.03 \\
\hline \multirow[t]{2}{*}{ Multivariable } & Obesity & $3.0(1.7,5.3)$ & $<0.0001$ \\
\hline & Race (Black) & $0.3(0.1,0.9)$ & 0.03 \\
\hline \multicolumn{4}{|l|}{$19+$ Years } \\
\hline \multirow[t]{4}{*}{ Univariable } & Smoking $^{d}$ & $1.3(1.04,1.6)$ & $<0.0001$ \\
\hline & $\begin{array}{l}\text { Family income } \\
<\$ 50,000\end{array}$ & $1.4(1.1,1.7)$ & 0.003 \\
\hline & Race (Blacks) & $2.4(1.2,4.7)$ & 0.01 \\
\hline & Morbid obesity & $1.7(1.1,2.6)$ & 0.02 \\
\hline \multirow[t]{3}{*}{ Multivariable } & Smoking & $1.3(1.04,1.6)$ & 0.02 \\
\hline & Morbid obesity & $1.7(1.1,2.6)$ & 0.02 \\
\hline & Race (Black) & $4.0(2.0,8.0)$ & $<0.001$ \\
\hline
\end{tabular}

Variables considered are as follows: age, gender, race, income, activity, flu vaccination, smoke exposure and obesity. Variables were fit singly (univariate modelling), and then a stepwise procedure examined all the variables together.

${ }^{\text {a}}$ Family income was self reported as total annual family income with reference group income of $\$ 50,000$ or more per year.

bThe definition for obesity was appropriate to the age group considered and varied for those $<19$ and adults. ${ }^{37,38}$ Non-obese was the reference group.

${ }^{\mathrm{C}}$ Race was self-reported race. White was the reference group.

${ }^{\mathrm{d}}$ Smoking was self reported; current smoking status and nonsmoking was the reference group.

parents and others in smoking-cessation efforts. ${ }^{17-19}$ Every asthma visit represents an intervention opportunity.

At every age, being overweight or obese was associated with adverse asthma outcomes: having out-of-control asthma in children and adults, and experiencing asthma exacerbations in tweens and adults. Compared with the US obesity rates reported from the CDC's National Health and Nutrition Examination Survey, these children and tweens with asthma were 1.2-1.3 times more likely to be obese (>95\% of expected weight for age). ${ }^{26}$ The problem was even more pronounced in adults in whom obesity and morbid obesity rates were 1.5 times that of the US adult population. ${ }^{27,28}$ Other studies have also linked obesity with adverse asthma outcomes, including poorer control and increased asthma severity. ${ }^{42}$ Our data highlight an important opportunity for family physicians and paediatricians to discuss the impact of weight, eating and activity choices on adverse asthma outcomes that can be disruptive and expensive for families., 3,6 Unfortunately, limited data exist to recommend simple solutions, with most weight management programmes requiring intensive longterm intervention. ${ }^{43,44}$

Among this group of people with asthma, activity levels were reported to be moderate to low and to decrease to very low levels in tween girls and women. Up to $20 \%$ of the children and tweens and over $33 \%$ of women reported no days of even $15 \mathrm{~min}$ of activity in a week. Current US CDC recommendations for the general health of children, adolescents and adults include at least 60 min of moderate or more strenuous aerobic activity each day with added muscle strengthening and bone strengthening pursuits. $^{33,34}$ Primary care physicians and other clinicians have 
an opportunity to discuss the impact of activity on asthma and weight management. ${ }^{16}$

Patients' willingness to engage in discussions related to changing behaviours may be based on their perceptions of health (e.g., asthma control) and personal goals. ${ }^{45}$ As has been reported previously, ${ }^{46}$ this group of parents and patients also appeared to overestimate their asthma control. This may represent a personal preference related to the perceived burden versus benefit of behaviours or lifestyle choices that could improve asthma control. Conversely, it may represent a misunderstanding of what has to be accepted as 'normal' for a person with asthma. Awareness of the gap between patient/parent and health professionals' assessments of asthma status may represent another important opportunity for addressing both medication use and lifestyle changes to address factors adversely affecting asthma including obesity, smoking and activity.

Strengths and limitations of this study

The strengths of this study include the large sample size, the inclusion of patients from a wide diversity of regions of the United States, and multiple practices. We collected data on several health-related conditions that are seldom addressed in pragmatic asthma trials including secondhand smoke exposure, activity and obesity. Our study also has several limitations including responder bias. As reported previously, ${ }^{7}$ the responders to the initial survey differed from the nonresponders in some characteristics that we could identify from the medical record reviews, including age, gender and BMl, with the nonresponders more likely to be men, younger and to have a BMI in the overweight or obese range. It is not clear how age and gender might affect the factors we found to be associated with poorer asthma outcomes. However, it is possible that the decreased responder rate for obese individuals may have resulted in an underestimation of the impact of obesity on the outcomes of interest. Some of the factors reported are not modifiable in the usual health-care setting but could be used to alert health-care professionals to the increased likelihood of poor asthma outcomes and to search for modifiable factors such as inability to buy healthier foods, avoid smoke exposure or the lack of a safe place to do physical activities.

Implications for future research, policy and practice

Future studies that address pragmatic approaches to improved asthma outcomes need to go beyond medication-based asthma management to address other modifiable factors and lifestyle choices. Specifically, prospective studies to further establish causality between lifestyle choices and asthma outcomes are required, as are clinical trials to demonstrate the ability of interventions to increase exercise and reduce weight and smoke exposure to improve asthma control. Primary care is the appropriate site to encompass approaches to most of the patient's health-care needs, and these data stress the continuing need to address obesity, activity, secondhand smoke exposure and smoking in asthma management.

\section{Conclusions}

Among this sample of primary care patients with asthma, inadequate asthma control and risk of exacerbation were associated with factors for which interventions are possible: smoking, exposure to secondhand smoke, low levels of physical activity and obesity. These findings suggest that primary care health professionals consider these potentially modifiable elements of asthma management during each visit.

\section{ACKNOWLEDGEMENTS}

The authors thank Ms Jeni Johnson, MBA, for her help in the preparation of the manuscript for submission.

\section{CONTRIBUTIONS}

All authors contributed to the work and were involved in the study design, data collection, statistical analysis and writing of the manuscript. Dr Barbara Yawn is the corresponding author.

\section{COMPETING INTERESTS}

The authors declare no conflict of interest.

\section{FUNDING}

This original research article was funded by the Agency for HealthCare Quality and Research, USA (R01 HSO-18431).

\section{REFERENCES}

1 Asthma: Data, Statistics, and Surveillance. Center for Disease Control and Prevention (2013). http://www.cdc.gov/asthma/asthmadata.htm. Accessed 15 January 2015.

2 Yawn BP, Wollan P, Kurland M, Scanlon P. A longitudinal study of the prevalence of asthma in a community population of school-age children. J Pediatr 2002; 140: 576-581.

3 Sadatsafavi M, Rousseau R, Chen W, Zhang W, Lynd L, FitzGerald JM et al. The preventable burden of productivity loss due to suboptimal asthma control: a population-based study. Chest 2014; 145: 787-793.

4 Sullivan PW, Ghushchyan VH, Slejko JF, Belozeroff V, Globe DR, Lin SL. The burden of adult asthma in the United States: evidence from the Medical Expenditure Panel Survey. J Allergy Clin Immunol 2011; 127: 363-369, e1-3.

5 National Ambulatory Medical Care Survey: 2010 Summary Tables. Centers for Disease Control and Prevention Website. http://www.cdc.gov/nchs/data/ahcd/ namcs_summary/2010_namcs_web_tables.pdf. Accessed 23 January 2015.

6 Rabe KF, Adachi M, Lai CKW, Soriano JB, Vermeire PA, Weiss KB et al. Worldwide severity and control of asthma in children and adults: the global asthma insights and reality surveys. J Allergy Clin Immunol 2004; 114: 40-47.

7 Lawson JA, Janssen I, Bruner MW, Hossain A, Pickett W. Asthma incidence and risk factors in a national longitudinal sample of adolescent Canadians: a prospective cohort study. BMC Pulm Med 2014; 14: 51.

8 Strina A, Barreto ML, Cooper PJ, Rodrigues LC. Risk factors for non-atopic asthma/ wheeze in children and adolescents: a systematic review. Emerg Themes Epidemiol 2014; 11: 5.

9 Smith LA, Hatcher-ross JL, Wertheimer R, Kahn RS. Rethinking race/ethnicity, income, and childhood asthma: racial/ethnic disparities concentrated among the very poor. Public Health Rep 2005; 120: 109-116.

10 Wechsler ME, Castro M, Lehman E, Chinchilli VM, Sutherland ER, Denlinger L et al. Impact of race on asthma treatment failures in the asthma clinical research network. Am J Respir Crit Care Med 2011; 184: 1247-1253.

11 Gamble C, Talbott E, Youk A, Holguin F, Pitt B, Silveira L et al. Racial differences in biologic predictors of severe asthma: data from the Severe Asthma Research Program. J Allergy Clin Immunol 2010; 126: 1149-1156, e1.

12 Ciprandi G, Schiavetti I, Bellezza fontana R, Sorbello V, Ricciardolo FL. Overweight and obesity as risk factors for impaired lung function in patients with asthma: a real-life experience. Allergy Asthma Proc 2014; 35: e62-e71.

$13 \mathrm{Kim} \mathrm{S}$, Camargo CA. Sex-race differences in the relationship between obesity and asthma: the behavioral risk factor surveillance system, 2000. Ann Epidemiol 2003; 13: 666-673.

14 Holguin F, Bleecker ER, Busse WW, Calhoun WJ, Castro M, Erzurum SC et al. Obesity and asthma: an association modified by age of asthma onset. J Allergy Clin Immunol 2011; 127: 1486-1493, e2.

15 Chaudhuri R, Livingston E, McMahon AD, Thomson L, Borland W, Thomson NC. Cigarette smoking impairs the therapeutic response to oral corticosteroids in chronic asthma. Am J Respir Crit Care Med 2003; 168: 1308-1311.

16 Eichenberger PA, Diener SN, Kofmehl R, Spengler CM. Effects of exercise training on airway hyperreactivity in asthma: a systematic review and meta-analysis. Sports Med 2013; 43: 1157-1170.

17 Comhair SA, Gaston BM, Ricci KS, Hammel J, Dweik RA, Teaque WG et al. Detrimental effects of environmental tobacco smoke in relation to asthma severity. PLOS ONE 2011; 6: e18574. 
18 Oh SS, Tcheurekdjian H, Roth LA, Nguyen EA, Sen S, Galanter JM et al. Effect of secondhand smoke on asthma control among black and Latino children. J Allergy Clin Immunol 2012; 129: 1478-1483, e7.

19 Borrelli B, Mcquaid EL, Wagener TL, Hammond SK. Children with asthma versus healthy children: differences in secondhand smoke exposure and caregiver perceived risk. Nicotine Tob Res 2014; 16: 554-561.

20 Butz AM, Matsui EC, Breysse P, Curtin-Brosnan J, Eggleston P, Diette G et al. A randomized trial of air cleaners and a health coach to improve indoor air quality for inner-city children with asthma and secondhand smoke exposure. Arch Pediatr Adolesc Med 2011; 165: 741-748.

21 Yawn BP, Bertram S, Kurland M, Wollan P, Graham D, Littlefield D et al. Protocol for the asthma tools study: a pragmatic practice-based research network trial. Prag Obs Res 2013; 4: 7-18.

22 Yawn BP, Bertram S, Wollan P. Introduction of Asthma APGAR tools improve asthma management in primary care practices. J Asthma Allergy 2008; 1: 1-10.

23 Rank MA, Bertram S, Wollan P, Yawn RA, Yawn BP. Comparing the asthma APGAR system with the Asthma Control Test ${ }^{\mathrm{TM}}$ in a multicenter primary care sample. Mayo Clin Proc 2014; 89: 917-925.

24 Nathan RA, Sorkness CA, Kosinski M, Schatz M, Li JT, Marcus P et al. Development of the asthma control test: a survey for assessing asthma control. J Allergy Clin Immunol 2004; 113: 59-65.

25 Clinical Growth Chart. Centers for Disease Control and Prevention Website. http://www.cdc.gov/growthcharts/clinical_charts.htm. Accessed 17 February 2015.

26 Overweight and Obesity: Childhood Overweight and Obesity. Centers for Disease Control and Prevention Website. http://www.cdc.gov/obesity/childhood/index. html. Accessed 17 February 2015.

27 Overweight and Obesity: Adult Obesity Facts. Centers for Disease Control and Prevention Website. http://www.cdc.gov/obesity/data/adult.html. Accessed 16 January 2015.

28 Defining Overweight and Obesity in Adults. Centers for Disease Control and Prevention Website. http://www.cdc.gov/obesity/adult/defining.html. Accessed 9 September 2015.

29 Behavioral Risk Factor Surveillance System. Centers for Disease Control and Prevention Website. http://www.cdc.gov/brfss/questionnaires.htm. Accessed 17 February 2015.

30 National Health Interview Survey. Centers for Disease Control and Prevention http://www.cdc.gov/nchs/nhis/nhis_questionnaires.htm. Accessed 17 February 2015

31 Agency for Healthcare Research and Quality. Medical Expenditure Panel Survey. US Department of Human Services Website. http://meps.ahrq.gov/mepsweb/. Accessed 17 February 2015.

32 Booth ML. Assessment of Physical Activity: An Interantional Perspective. Research Quarterly for Exercise and Sport 2000; 71: s114-s120.
33 How Much Physical Activity do Children Need. Centers for Disease Control and Prevention Website. http://www.cdc.gov/physicalactivity/everyone/guidelines/ children.html. Accessed 17 February 2015.

34 How much physical activity do adults need? Centers for Disease Control and Prevention Website. http://www.cdc.gov/physicalactivity/basics/adults/index.htm. Accessed 7 July 2015.

35 National Heart Lung and Blood Institute. Asthma Guidelines. US Department of Heath and Human Services. https://www.nhlbi.nih.gov/health-pro/resources/ lung/naci/asthma-info/asthma-guidelines.htm. Accessed 13 February, 2015.

36 The 2011 HHS Poverty Guidelines. US Department of Health and Human Services. http://aspe.hhs.gov/poverty/11 poverty.shtml. Accessed 17 February 2015.

37 Home: About SmokeFree. US Department of Health and Human Services. http://smokefree.gov/. Accessed 17 February 2015.

38 Lemmens V, Oenema A, Knut IK, Brug J. Effectiveness of smoking cessation interventions among adults: a systematic review of reviews. Eur J Cancer Prev 2008; 17: 535-544.

39 Current Cigarette Smoking Among US Adults Aged 18 Years and Older. Centers for Disease Control and Prevention. http://www.cdc.gov/tobacco/campaign/tips/ resources/data/cigarette-smoking-in-united-states.html. Accessed 11 February 2015.

40 Rank MA, Wollan P, Li JT, Yawn BP. Trigger recognition and management in poorly controlled asthmatics. Allergy Asthma Proc 2010; 31: 99-105.

41 Okuyemi K, Nollen N, Ahluwali J. Interventions to facilitate smoking cessation. Am Fam Physician 2006; 74: 262-271.

42 Ford EF. The epidemiology of obesity and asthma. J Allergy Clin Immunol 2005; 115: 897-909.

43 Overweight and Obesity: Tools and Resources. Centers for Disease Control and Prevention Website. http://www.cdc.gov/nccdphp/dnpao/state-local-programs/ index.html. Accessed 17 February 2015.

44 Saguil A, Stephens M. Interventions to prevent childhood obesity. Am Fam Physician 2012; 86: 30-32.

45 Smith L, Alles C, Lemay K, Reddel H, Saini B, Bosnic-Anticevich S et al. The contribution of goal specificity to goal achievement in collaborative goal setting for the management of asthma. Res Social Adm Pharm 2013; 9: 918-929.

46 Yawn BP, Fryer GE, Lanier D. Asthma severity: the patient's perspective. J Asthma 2004; 41: 623-630.

(C) This work is licensed under a Creative Commons Attribution 4.0 the images or other third party material in this rticle are included in the article's Creative Commons license, unless indicated otherwise in the credit line; if the material is not included under the Creative Commons license, users will need to obtain permission from the license holder to reproduce the material. To view a copy of this license, visit http://creativecommons.org/licenses/ by/4.0/

Supplementary Information accompanies the paper on the npj Primary Care Respiratory Medicine website (http://www.nature.com/npjpcrm) 